\title{
Introduction to the Special Issue Dedicated to the Memory of Alan J. Hunt
}

It is with both tremendous sadness and great pride that we commemorate the anniversary of the passing Prof. Alan J. Hunt of the Department of Biomedical Engineering at the University of Michigan on October 30, 2012 from an extremely rare form of appendix cancer at the age of 49 . Alan was a great friend and colleague with an exceptional passion for science, and who brought great joy to those of us who were fortunate to have known him. He was a founding member of the board of Associate Editors of Cellular and Molecular Bioengineering, and helped bring this journal into existence. With the support of CMBE Editorin-Chief, Michael King, we are pleased to serve as guest editors, and to present a special issue of CMBE that commemorates the contributions of Alan Hunt to the field of cellular and molecular bioengineering. Contained in this issue is a series of articles by former students, collaborators, and mentors that we believe capture the spirit of Alan's approach to science. Alan especially valued quantification and a physically based framework for some of the most complex processes in cell biology, and we believe these articles reflect these values. We hope that this special issue will inspire others to continue in this quantitative, physics-based approach to demystify the inner workings of the cell.

\author{
WiLl HANCOCK \\ Department of Bioengineering, \\ Pennsylvania State University, \\ State College, PA, USA
}

DAVID J. ODDE

Department of Biomedical Engineering University of Minnesota, Minneapolis, MN, USA Electronic mail: oddex002@umn.edu

DAVID SEPT

Department of Biomedical Engineering, University of Michigan,

Ann Arbor, MI, USA 